\title{
A computational model for optimum process parameters based on factory data and overall liquor rating of black tea
}

\author{
Debashis Saikia $^{*}$, P. K. Boruah ${ }^{2}$ and Utpal Sarma ${ }^{3}$ \\ Assistant Professor, Department of Instrumentation and USIC, Gauhati University, Guwahati, (Assam), India ${ }^{1}$ \\ Professor(Retd.), Department of Instrumentation and USIC, Gauhati University, Guwahati, (Assam), India ${ }^{2}$ \\ Professor, Department of Instrumentation and USIC, Gauhati University, Guwahati, (Assam), India ${ }^{3}$
}

Received: 03-November-2020; Revised: 18-December-2020; Accepted: 20-December-2020

(C)2020 Debashis Saikia et al. This is an open access article distributed under the Creative Commons Attribution (CC BY) License, which permits unrestricted use, distribution, and reproduction in any medium, provided the original work is properly cited.

\begin{abstract}
This paper presents a model to find the optimum process conditions for tea manufacturing as well as to predict the black tea quality by implementing a network based tea process parameters monitoring and data logging system. Here, the developed instrument is first calibrated and then implemented to collect the process parameters of tea fermentation and drying. The corresponding tea quality also termed as overall liquor rating (OLR) is collected from tea tasters. Principal component analysis (PCA) is carried out to visualize the pattern of the process parameters. The first two principal components stored $93 \%$ useful information whereas more than 6\% useful information is stored in the 3rd principal component. It is found from the PCA that maximum samples are clustered in well-defined manner. To study the correlation of the process parameters with OLR, a computational model based on Artificial Neural Network (ANN) has been developed. Non cross validation (NCV) ANN and tenfold cross validation (TFCV) ANN models have been trained and tested. Process conditions and corresponding OLR are taken as input and target for the model. $74 \%$ classification rate with root mean square error (RMSE) of 0.13 is obtained from the study. The optimum process conditions are found out from the model.
\end{abstract}

\section{Keywords}

Tea quality, Back-propagation neural network, Black tea, Fermentation, Drying.

\section{Introduction}

Tea quality evaluation is a complex task due to its dependency on the enumerable parameters, broadly classified as chemical and physical. The important physical factors are ambient temperature and relative humidity $(\mathrm{RH})$ during fermentation, aeration in fermentation, tea dryer temperature etc. The plucked leaves passed through several processing stages like withering, Crush-Tear-Curl (CTC), fermentation, drying, sorting and grading etc. Biochemical reactions that start right after plucking the leaves from the bush and the physical condition of the processes are responsible for the quality improvement. The black tea processing flow is shown in Figure 1.

All these processes and their process conditions are responsible for quality of tea. However, fermentation and drying conditions play the most important role.

*Author for correspondence

220
In the fermentation process tea colour and flavour are changed from green to coppery brown and grassy to floral smell respectively [1]. It is an oxidation process and it starts with exposing the leaves to air after CTC. The key parameters that affect the fermentation process are ambient temperature and $\mathrm{RH}$. The optimum process parameters are the matter of interest for fermentation process which is vital in producing superior quality tea. Over and under fermentation can result in declined quality. Another important parameter in fermentation is the fermentation time. Pioneering works were done by Bhattacharya et al in $[2,3]$. Bhattacharya et al. [2] used an electronic nose based technique to monitor the fermentation process of black tea and correlated these data with the results of colorimetric tests and human expert evaluation. It is reported in [3] that the optimum fermentation time estimated by electronic nose based technique.

In the process of drying, enzyme reactions in the earlier stages are terminated, free moisture is 
removed and new compounds are produced by the application of heat. Optimal use of heat can give the best result in the output quality. In [4], it is studied that exposure of heat should be minimum $80{ }^{\circ} \mathrm{C}$ to get good quality tea and maximum $120{ }^{\circ} \mathrm{C}$ can be tolerated for 1 minute. This study is carried out for fluidised bed dryer. However, temperature above $110^{\circ} \mathrm{C}$ may be considered as the reason of the declined quality, they concluded. Therefore, monitoring of the inlet air temperature of the dryer is utmost important for maintaining tea quality [5].

Conventionally, tea tasters evaluate the tea quality of (a) dry leaf (b) infused leaf and (c) Cup characteristics based on tea liquor. Several factors such as size, appearance, colour, style, fibre content of the dry leaves are investigated to determine dry leaf quality. The tea leaf residue also known as infused tea. It is visually investigated where colour and brightness are taken into account. The assessment of tea liquor is done by visual means and also by the taste. This is one of the most important characteristics where the same cup is tasted twice, without milk and with milk. The following parameters are taken into account for the assessment of tea liquor

1.Briskness (astringency),

2.Strength,

3.Body (thickness of the liquor),

4.Brightness of the liquor,

5.Colour with milk,

6.Flavor with milk.
The final tea quality also known as overall liquor rating (OLR) is expressed as a numeric value on a scale in the range of 0 to 10 . OLR summarises all the liquor quality parameters into a single numeric expression. The tea tasters' marks after assessing the tea quality are depicted in the Table 1.

This particular work is intended to make a model for finding optimum tea process conditions which leads to produce quality tea. Here, a computational model based on ANN to correlate the tea process parameters of fermentation and drying process with the OLR of tea is developed.

The main objectives are as follows-

1. Collection of tea process parameters from the tea factory by implementing the developed network based instrumentation system and manual collection of corresponding OLR

2. Investigation on the pattern of the process parameters

3. Develop an ANN model to establish a relation between tea process parameters and OLR

4. Validate the ANN model with different techniques

5. Prediction of tea quality from the recorded data

6 . Finding optimum process condition

This paper is organized in the following manner: Section 1 present introduction and section 2 describes the related literature review. Section 3 deals with the methods and materials. Section 4 describes the results and data analysis. Discussions are presented in section 5 and Conclusion and future scope is discussed in section 6 .

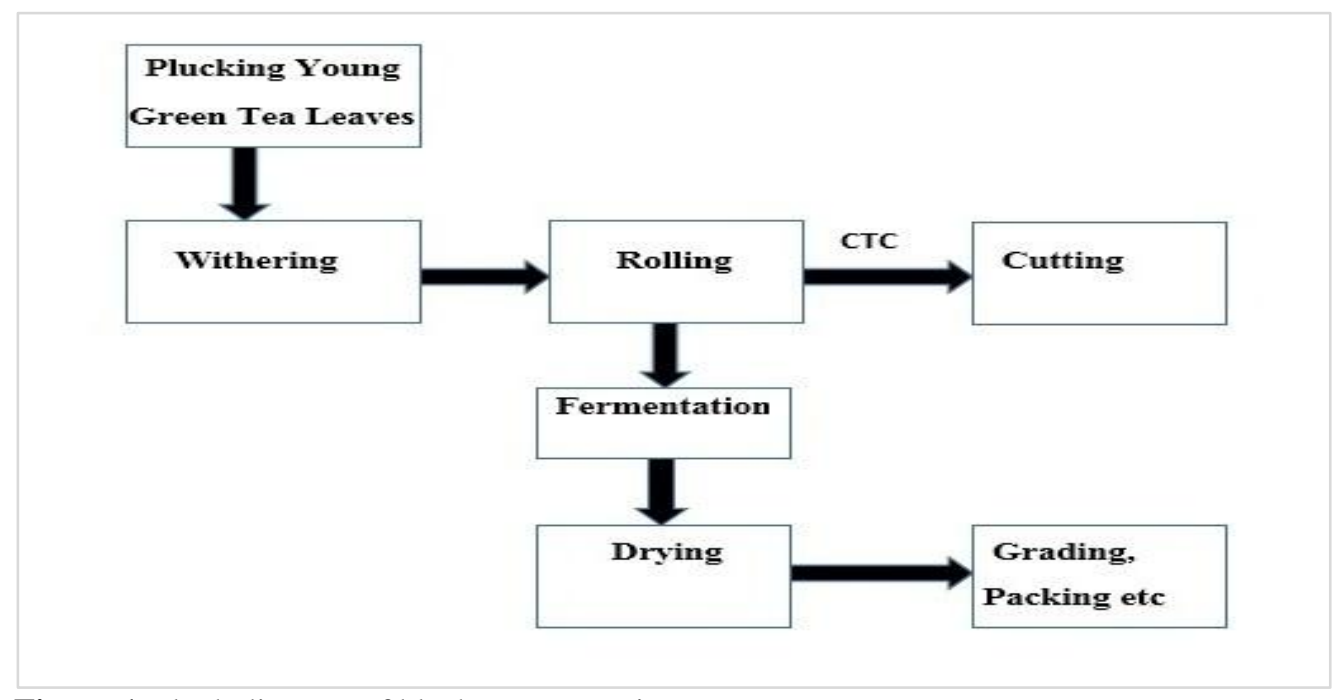

Figure 1 Block diagram of black tea processing stages 
Debashis Saikia et al.

Table 1 Detailed representation tea tasters' marks after assessing the tea quality

\begin{tabular}{|c|c|c|c|c|c|c|c|c|c|c|c|c|c|c|}
\hline \multirow{2}{*}{$\begin{array}{l}\text { Sample } \\
\text { Date } \\
(\mathrm{mm} / \mathrm{dd} / \mathrm{yy} \\
\text { yy) }\end{array}$} & \multirow{2}{*}{$\begin{array}{l}\text { Leaf } \\
\text { Bloo } \\
\text { m }\end{array}$} & \multirow[b]{2}{*}{$\begin{array}{l}\text { Colo } \\
\text { ur }\end{array}$} & \multirow[b]{2}{*}{$\begin{array}{l}\text { Sty } \\
\text { le }\end{array}$} & \multirow[b]{2}{*}{$\begin{array}{l}\text { Fib } \\
\text { re }\end{array}$} & \multicolumn{2}{|c|}{ Infusion } & \multicolumn{7}{|c|}{ Liquor Characteristics } & \multirow{2}{*}{$\begin{array}{l}\text { OL } \\
\mathbf{R}\end{array}$} \\
\hline & & & & & $\begin{array}{l}\text { Brig } \\
\text { ht }\end{array}$ & $\begin{array}{l}\text { Rema } \\
\text { rk }\end{array}$ & $\begin{array}{l}\text { Bris } \\
\mathbf{k}\end{array}$ & $\begin{array}{l}\text { Streng } \\
\text { th. }\end{array}$ & $\begin{array}{l}\text { Bod } \\
y\end{array}$ & $\begin{array}{l}\text { Brig } \\
\text { ht }\end{array}$ & $\begin{array}{l}\text { Rema } \\
\text { rk }\end{array}$ & $\begin{array}{l}\text { CW } \\
\text { M }\end{array}$ & $\begin{array}{l}\text { FW } \\
\text { M }\end{array}$ & \\
\hline $08 / 01 / 2014$ & 1.5 & $\begin{array}{l}\text { BRB } \\
\text { L }\end{array}$ & GR & SEF & 6 & $\begin{array}{l}\text { SLGR } \\
\mathrm{N}\end{array}$ & 4.5 & 3 & 2 & 4 & MOD & DY & 3 & 3.3 \\
\hline $08 / 02 / 2014$ & 1.5 & BRW & GR & SEF & 5.5 & $\begin{array}{l}\text { SLGR } \\
\mathrm{N}\end{array}$ & 5 & 3.5 & 2.5 & 3.5 & FAIR & DY & 5 & 3.9 \\
\hline $08 / 03 / 2014$ & 1.5 & BRW & GR & SEF & 4 & $\begin{array}{l}\text { SLGR } \\
\mathrm{N}\end{array}$ & 5 & 3.5 & 3 & 4.5 & FAIR & DY & 5 & 4.2 \\
\hline $08 / 07 / 2014$ & 1.5 & BRW & GR & SEF & 5.5 & $\begin{array}{l}\text { SLGR } \\
\mathrm{N}\end{array}$ & 4.5 & 3 & 1.5 & 4.5 & MOD & DY & 4 & 3.5 \\
\hline $08 / 08 / 2014$ & 1 & BRW & GR & SEF & 4.5 & $\begin{array}{l}\text { SLGR } \\
\mathrm{N}\end{array}$ & 5 & 3.5 & 3 & 5 & FLGD & DY & 5.5 & 4.4 \\
\hline $08 / 09 / 2014$ & 1 & BRW & GR & SEF & 5 & $\begin{array}{l}\text { SLGR } \\
\mathrm{N}\end{array}$ & 5 & 4 & 3.5 & 5.5 & FLGD & DY & 5 & 4.6 \\
\hline
\end{tabular}

[Bright: Brightness; Brisk: Briskness; CWM: Colour with Milk; FWM: Flavour with Milk; BRBL: Brownish Black; BRW: Brownish; GR: Grainy; SEF: Some Embedded Fiber; SLGRN: Slightly Greenish; MOD: Moderate; FLGD: Fairly Good; DY: Deep Yellow]

\section{Literature review}

Kumar et al. [6] implemented various analytical techniques to evaluate tea quality and compared with sensory methods. Samanta et al. [7] described the importance of fermentation time and temperature on biochemical changes of tea and finally on tea quality. Several developments were done by Sarma et al. to monitor $\mathrm{RH}$ and temperature of the fermentation room $[8,9,10]$ and dryer temperature [11].

Quantification of tea quality was done by several means and ANN is one of those techniques. Bhattacharyya et al. [3] implemented electronic nose based technique to determine optimum fermentation time. For this, they correlated the electronic nose data with the colorimetric as well as tea tasters' data. In another study by Xie et al. [12], it was investigated the feasibility of using hyperspectral imaging technique for non-destructive measurement of colour components of tea leaves and classify these during different drying periods. The result showed this technique is useful as an objective and nondestructive method to determine colour features and classify tea leaves at different drying periods. They used different statistical and soft computing methods for the stated purpose. One study [13] shows determination of black tea fanning grade using nearinfrared spectroscopy where 69 different fanning grades were collected from 10 different tea estates among which 50 samples were used as training samples and 19 samples were used for validation purpose. Partial least square (PLS) regression model was implemented for the purpose and the results showed that the near-infrared and PLS technique successfully built a regression model based on the training set samples and properly predicted the scores obtained by the organoleptic determinations of the three quality parameters including appearance, liquor, and infusion using samples from the validation set. Another study [14] deals with the development of an efficient technique for prediction of tea quality where electronic tongue signal processing using the sparse decomposition method was used. Sparse model coefficients were considered as characteristic attributes of the ET signals obtained for characterization of tea samples. Further experiments were carried out using three different types of pulse voltammetry which established the effectiveness of the stated method. Three different classifiers, viz. one versus one support vector machine, Vector valued regularised kernel function approximation and ANN, were employed on the sparse coefficients for the testing purpose. High classification accuracy of all the classifiers on three types of voltammetric measurement data validated the usefulness of the technique. The following are few works related to tea quality assessment-

a. Enhancement of prediction accuracies of tea quality by developing a framework for a multilevel fusion strategy using E-nose has been proposed and experimented [15].

b. The synergism among different types of aroma compounds was studied and evaluated using sensory analysis and E-nose for oolong tea infusion [16].

c. A hand held E-nose using metal oxide semiconductor gas sensor was developed to estimate the flavor of black tea [17]. 
d. A fusion approach combining E-nose, E tongue and E-eye with chemometric methods were applied for identification and prediction of tea quality qualitatively and quantitatively [18].

e. An in situ E-nose chemometric methods have been implemented for quantifying quality of black tea samples and found it a practical tool for classification [19].

f. Different clones of tea have been collected from different area of Nepal and studied their chemical activities such as phytochemical and antioxidant as well as sensory quality [20].

From all of the works cited above, it is seen that most of the works dealt with the final tea product. Researchers used e-nose and e-tongue in the final product and predicted the tea quality. But they are unable give any strategy for improving quality of tea.
Further, no works have been seen till now for quality improvement at its manufacturing stages. Few works were reported on development of monitoring system for process conditions of tea manufacturing.

\section{Methods and materials}

Detailed methodology of the experiment is depicted in Figure 2. First phase deals with the collection and pre-processing of the data to achieve the stated objective. Input data is then investigated for visualising its pattern using PCA. After that the NCV-ANN and TFCV-ANN models have been trained with the collected data. Finding optimum condition and tea quality classification can be done by using these models.

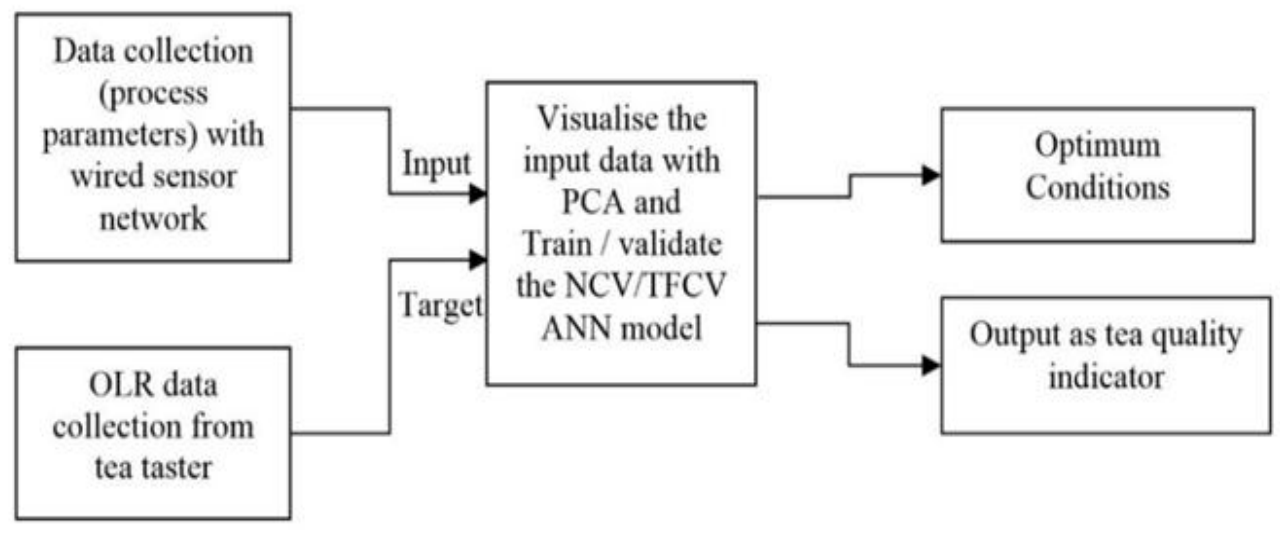

Figure 2 Block diagram representation of the detailed methodology

\subsection{Development of the instrumentation for the tea} factory

An RS 485 network based instrument to record different tea process parameters was developed by the author and reported in [21]. Basic block diagram of the instrument is shown in Figure 3. Four sensor nodes were developed for the factory, out of which three were used for the fermentation room and one based on thermocouple sensor was used for dryer temperature monitoring. Fermentation room monitoring nodes were able to record the $\mathrm{RH}$ and temperature.

The data from the sensor nodes were taken as input for the study. The descriptions of the data taken as input parameters are depicted in Table 2. 


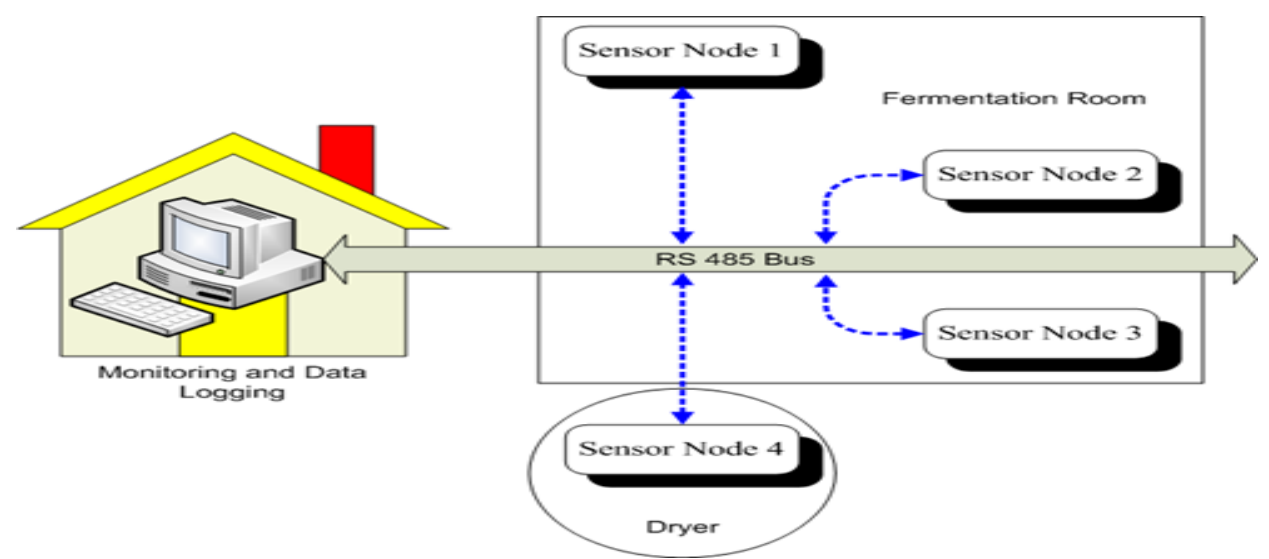

Figure 3 Block diagram representation of the instrumentation for the tea factory

Table 2 Description of the input parameters

\begin{tabular}{lll}
\hline Input parameters & Description & Symbol \\
\hline 1 & Temperature of the fermentation room provided by Sensor node 1 & T1 \\
\hline 2 & RH of the fermentation room provided by Sensor node 1 & RH1 \\
\hline 4 & Temperature of the fermentation room provided by Sensor node 2 & T2 \\
\hline 5 & RH of the fermentation room provided by Sensor node 2 & RH2 \\
\hline 6 & Temperature of the fermentation room provided by Sensor node 3 & T3 \\
\hline 7 & RH of the fermentation room provided by Sensor node 3 & RH3 \\
\hline
\end{tabular}

\subsection{Experimentation and data collection}

Experiments were carried out in a tea factory near Mangaldoi, Assam, India where the developed instrument was installed and operated. The system was tested for 3 months in the departmental laboratory before installation. The collected data were analysed for the period of 26th June 2014 to 5th January, 2015 and 18th March to 12th December, 2015. The trend of the collected data is shown in Figures 4, 5,6,7,8 Figure 5 and Figure 6 depict the average daily fermentation temperature, fermentation
RH and inlet temperature of dryer for the month of July, 2014. Figure 7 and Figure 8 represent the variation of fermentation room temperature and $\mathrm{RH}$ and inlet temperature of dryer for a single day i.e. 10 August/2014. Tea process parameters were collected from the installed instrumentation in the factory on a regular basis. The OLR of the tea sample is collected daily basis from tea tasting centre at Guwahati (Assam, India). They provide the OLR in terms of the scale of $0-10$ as discussed earlier.

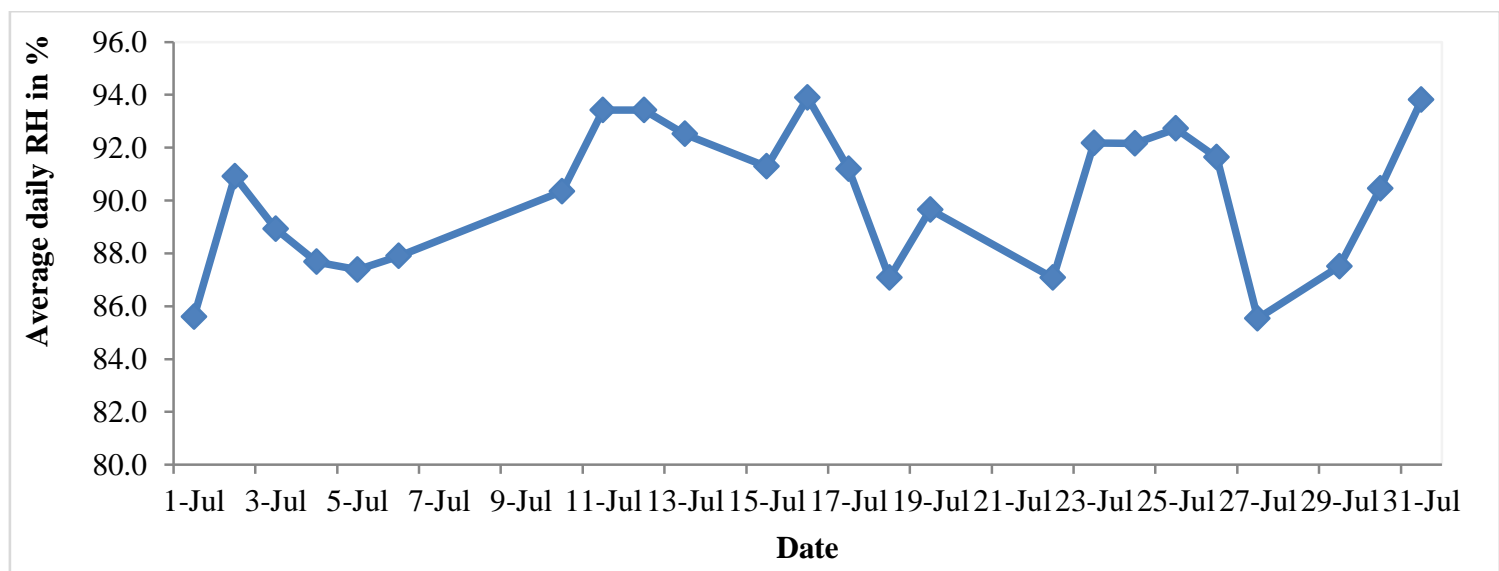

Figure 4 Variation of daily average RH of tea fermentation room for July/2014 


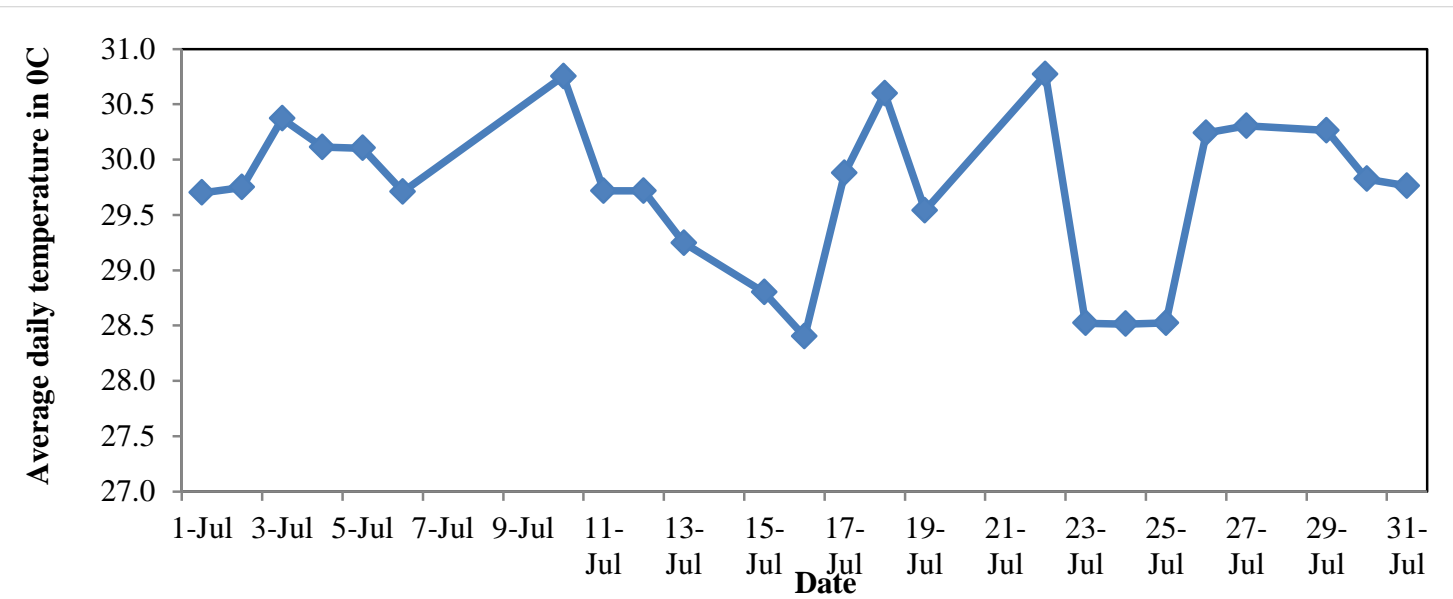

Figure 5 Variation of daily average temperature of tea fermentation room for July/2014

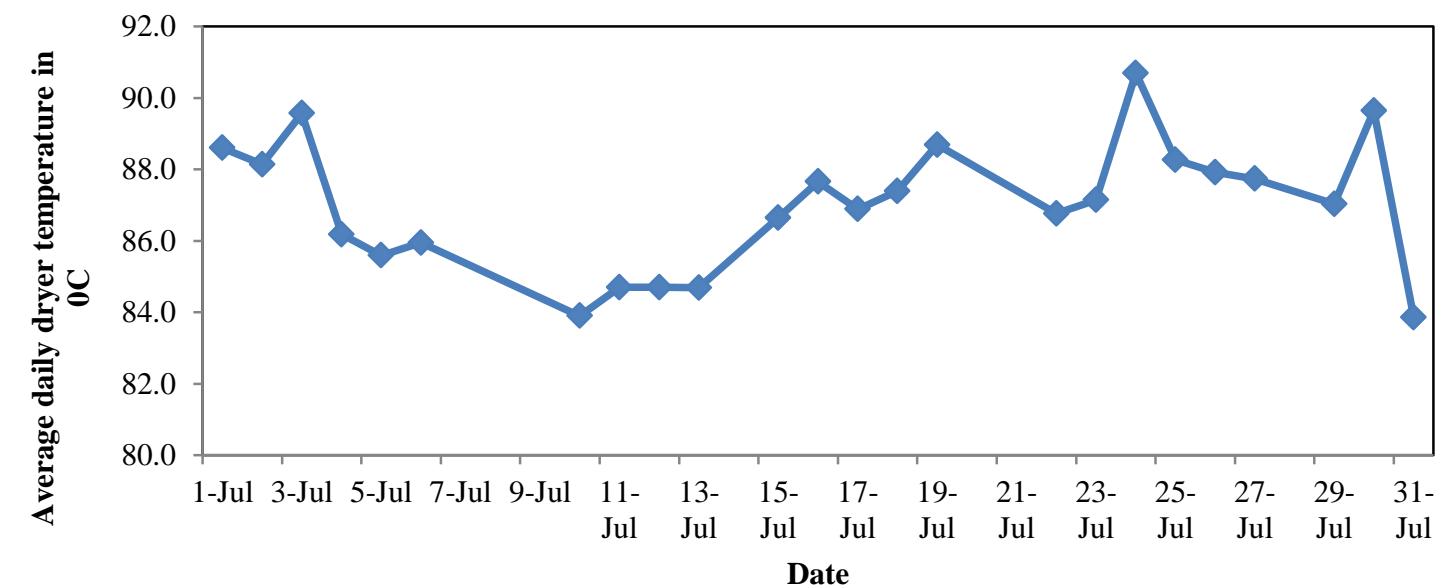

Figure 6 Variation of daily average dryer inlet temperature of tea factory for July/2014
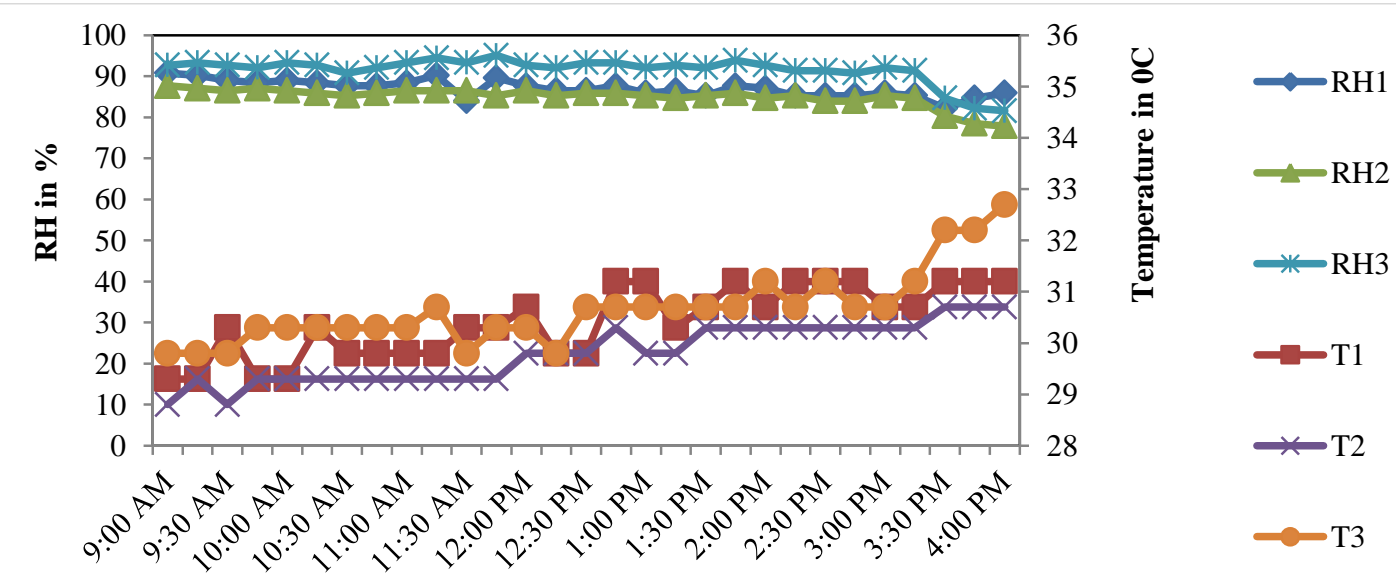

Time

Figure 7 Variation of fermentation room parameters, Date: 10.08.2014 


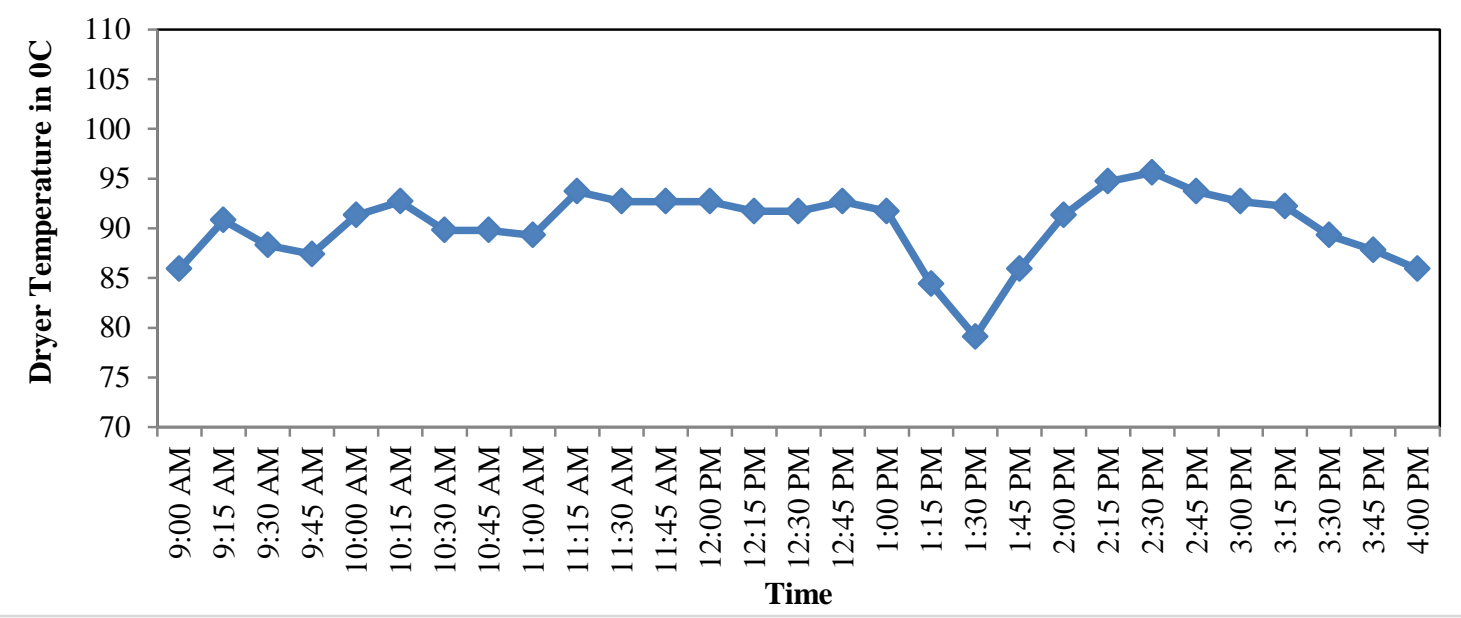

Figure 8 Variation of dryer inlet temperature, Date: 10.08.2014

\section{Results and data analysis}

Results and data analysis are discussed in the following sections.

\subsection{Principal component analysis (PCA)}

Visualisation of data pattern and projection of the data can be done by a dimensionality reduction technique known as principal component analysis (PCA). Principal component scores are used to reduce the dimension of dataset of high dimension. In this method, the overlapped information are discarded and useful information are extracted [2, 22, 23]. In this experiment 100 representative samples from 10 different tea qualities (10 samples from each
OLR) were taken. First two principal components stored more than $93 \%$ information while the first three principal components stored more than $99 \%$ useful information. Figure 9 depicts the plot to visualise the dimension spaces of first two principal components scores and Figure 10 depicts the same for the first three principal components scores. It is observed that samples with OLR 5.3, 3.6, 2.7,2, 1.7, and 0.3 are separated distinctly and the other four samples are overlapped. As the maximum samples are clustered in well-defined manner, so there is a possibility of correlation between the process parameters and OLR [24].

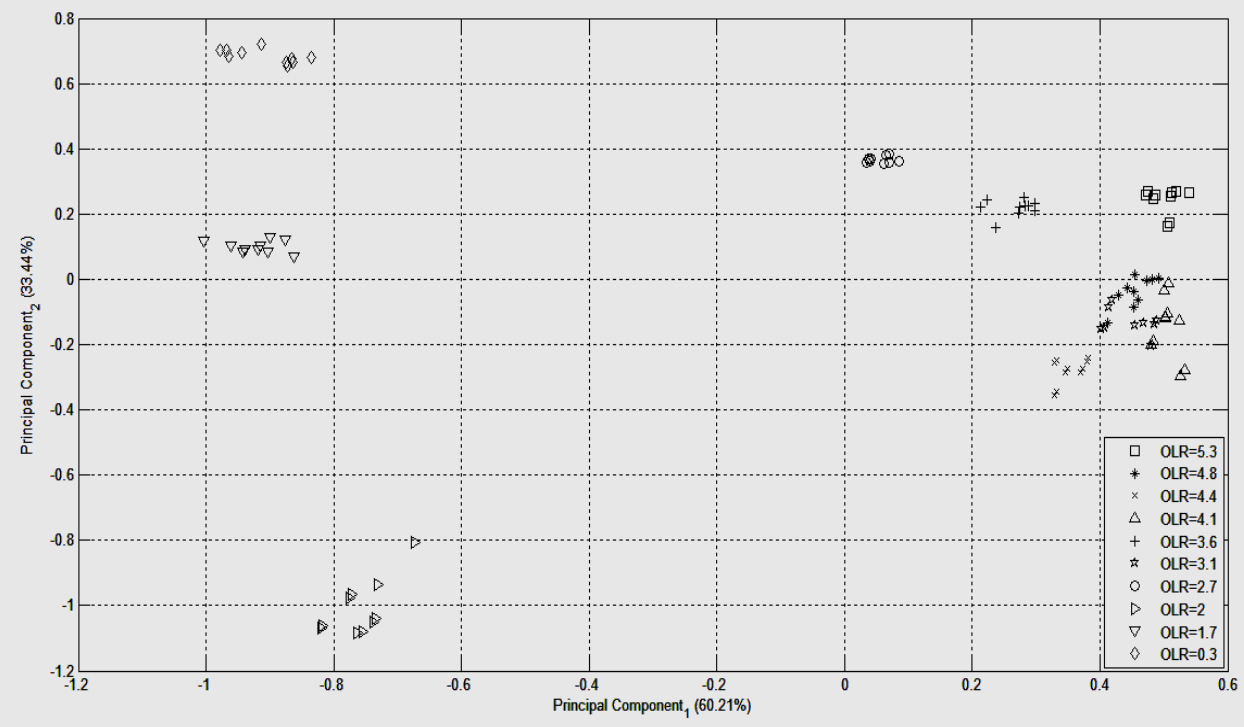

Figure 9 2-Dimensional Score cluster plot of first two principal components 


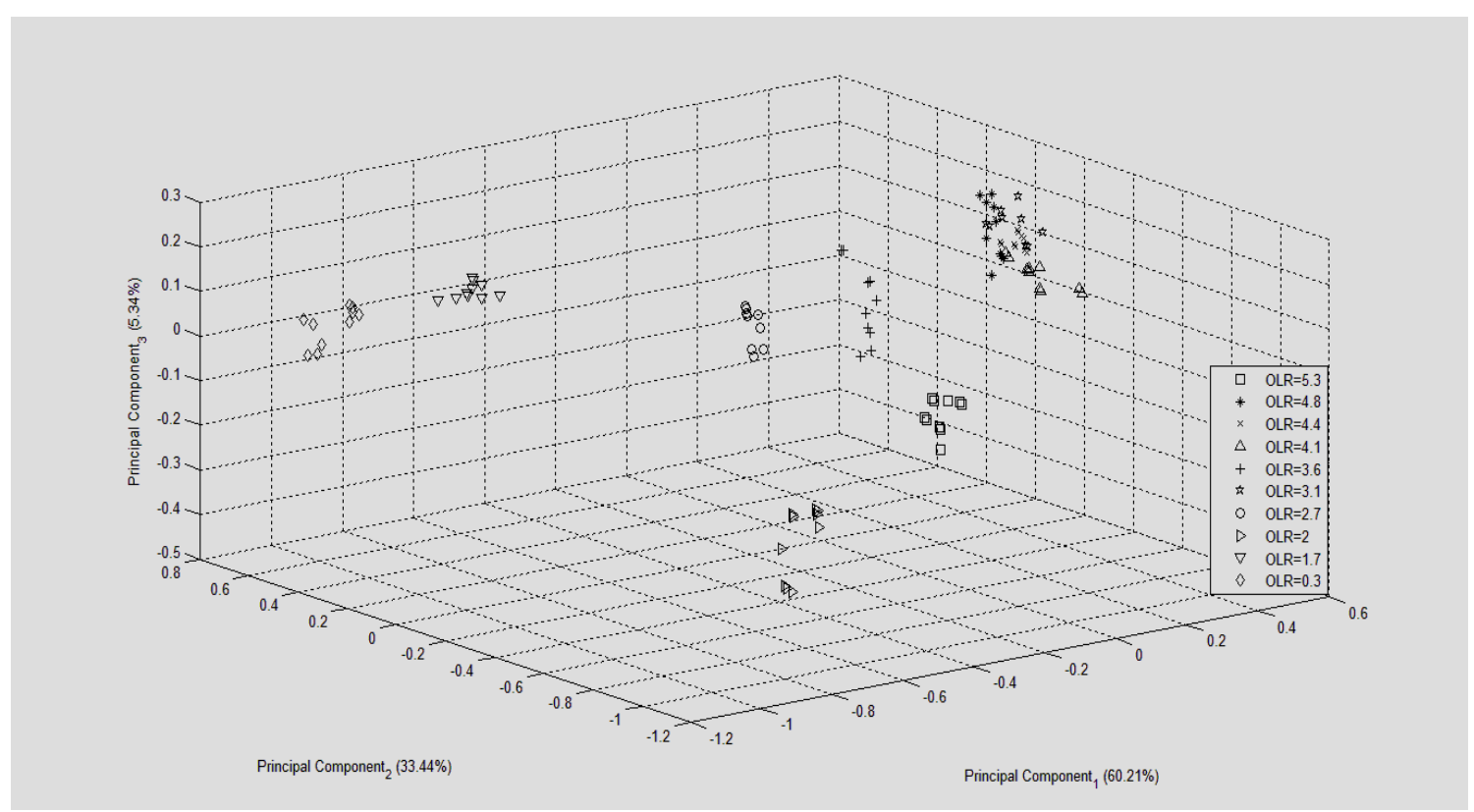

Figure 10 3-Dimensional score cluster plot of first three principal components

\subsection{Development of ANN model}

The ANN model was developed using backpropagation multi-layer perceptron (BP-MLP) for this purpose. It is a three-layer model comprising of a) input layer, b) hidden layer and c) output layer. The nodes of each layer are interconnected and their size may be varied. Hidden layer size may also vary. Nodes are associated with weights and form a network to process the inputs and obtained outputs are compared with the desired output. Weights are updated in accordance with the obtained output error. For this the gradient descent rule is followed. Thus the weights are always updated and network is trained by repeating the above process for the same dataset. [24-26].

Multiplication of each input by the weight matrix produces the output which is further multiplied by a transfer function in the hidden layer. Here, a sigmoid transfer function as shown below is used-

$F(s)=1 /(1+\exp (-s)$

Accordingly, the network weights are updated and biased in the direction of the negative gradient in BPMLP. Weights are updated as

$\mathrm{w}_{\mathrm{ik}}^{\mathrm{t}}=\mathrm{w}_{\mathrm{ik}}^{\mathrm{t}-1}-\eta\left(\partial \mathrm{E}_{\mathrm{k}} / \partial \mathrm{w}_{\mathrm{ik}}\right)$
Where, $w_{i k}^{t}$ is the new updated weight at $t^{\text {th }}$ iteration, $\mathrm{w}_{\mathrm{ik}}^{\mathrm{t}-1}$ is the weight at (t-1)th iteration, $\mathrm{E}_{\mathrm{k}}$ is the error at output node [25, 27].Details of this approach is depicted in Figure 11.

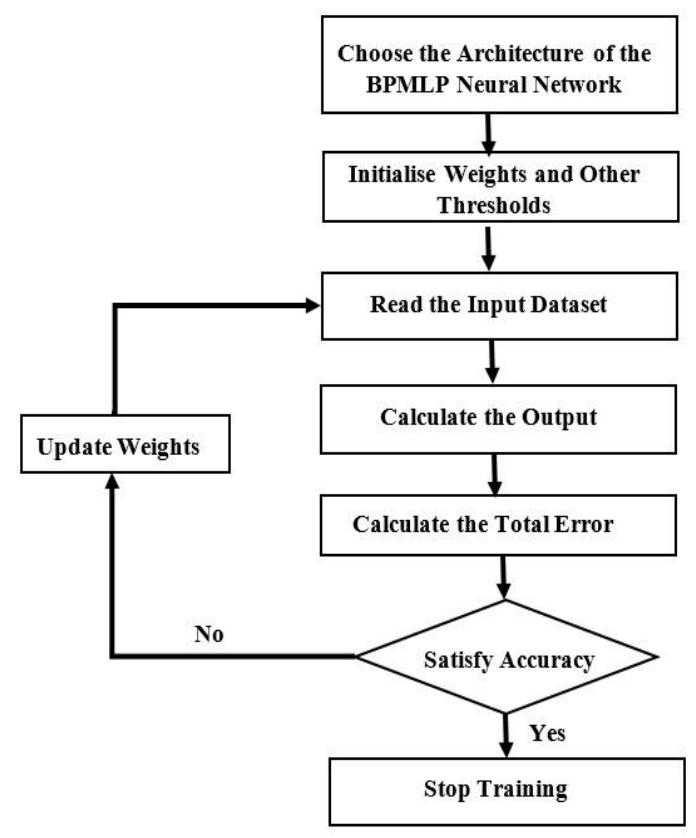

Figure 11 Flowchart of the BPMLP neural network algorithm 
NCV-ANN and TFCV-ANN models was developed and tested. In NCV-ANN, training and validation sets are fixed i.e. only one set of data is used for training the model and only one set of data is used for validation purpose. However, in case of TFCV-ANN, each data point appears once in the validation set and nine times in the training set [28]. In this method, the total dataset is subdivided in to ten subsets. The algorithm for choosing the data points are developed in such a way that $90 \%$ data points are used for training purpose and $10 \%$ is assigned for the validation of the model. One data point appears once in the validation set and nine times in the training set. The correlation coefficients are then averaged over these folds to get the performance of the model [29]. The detailed method is shown in Figure 12.

In case of NCV-ANN model the performance is estimated from a single fixed training and validation set. However, there will be a lot of variation in the performance estimate for different samples of data, or for different partitions of the data. Therefore, TFCVANN model is advantageous over NCV-ANN model which reduces this variation by averaging over ten different partitions, so the performance estimate is less sensitive to the partitioning of data.

\begin{tabular}{|c|c|c|c|c|c|c|c|c|c|c|}
\hline & set 1 & sset 2 & oset 3 & set 4 & abset 5 & abset 6 & bset 7 & abset 8 & Subset 9 & Subset 10 \\
\hline d) & minin & ainina & ining & inino & rinino & ainino & raining & raining & Training & Validation \\
\hline 1d 2 & & & & & & & & & & \\
\hline $\operatorname{ld} 3$ & & & & & & & & & & ining \\
\hline ld 4 & Train & Ginin & ining & & aining & & & raining & aining & raining \\
\hline Id 5 & & & & & & & & & & ining \\
\hline Id 6 & & & & & & & & & & eng \\
\hline Id 7 & & & & Validation & Training & Training & ining & ining & raining & raining \\
\hline 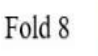 & & & lidation & & & & & & & raining \\
\hline 政 & & Validation & Training & & & & & & Training & Training \\
\hline Id 10 & Validation & Training & Training & Training & Training & Training & Training & Training & Training & Training \\
\hline
\end{tabular}

Figure 12 Ten-fold cross validation method [30]

4.3Training and performance of NCV-ANN model Here, a four layer BP-MLP model with single input layer, double hidden layer and one output layer was constructed. Different training algorithms were taken for the training purpose as depicted in Table 3. It is seen that Levenberg Marquardt training algorithm shows better result than the others, therefore, this training algorithm is chosen for further investigations. The input and the output layers are configured with the process parameters and OLR which were collected from tea factory and the tea tasters respectively. The input layer consists of seven nodes; the two hidden layers consist of ten nodes each and the output layer consists of a single node. Optimum BP-MLP model is shown in Figure 13. Since no standard rule was found to choose the number of hidden layers, number of nodes on the hidden layer and the network topology, so the optimum model was found from the trial and error method [30]. Different hidden layer sizes were tested for this case using the Levenberg Marquardt algorithm. Some of the cases are represented in Table 4.

The process parameters for 143 days (during 26th June, 2014 to 5th January, 2015and 18th March to 12th December, 2015) were taken for the purpose of developing the ANN model. The corresponding OLR was also taken in to account. Total 476490 numbers of data points were collected during the stated period. The collected data set was divided into two groups, the training and validation group. The training and validation data were subdivided using a suitable algorithm where $80 \%$ of the total data were assigned for training the network and $20 \%$ were assigned for validation purpose. The data were chosen randomly. More than $74 \%$ correct correlation was found from this analysis. The result from the optimum model is illustrated in Table 5. 


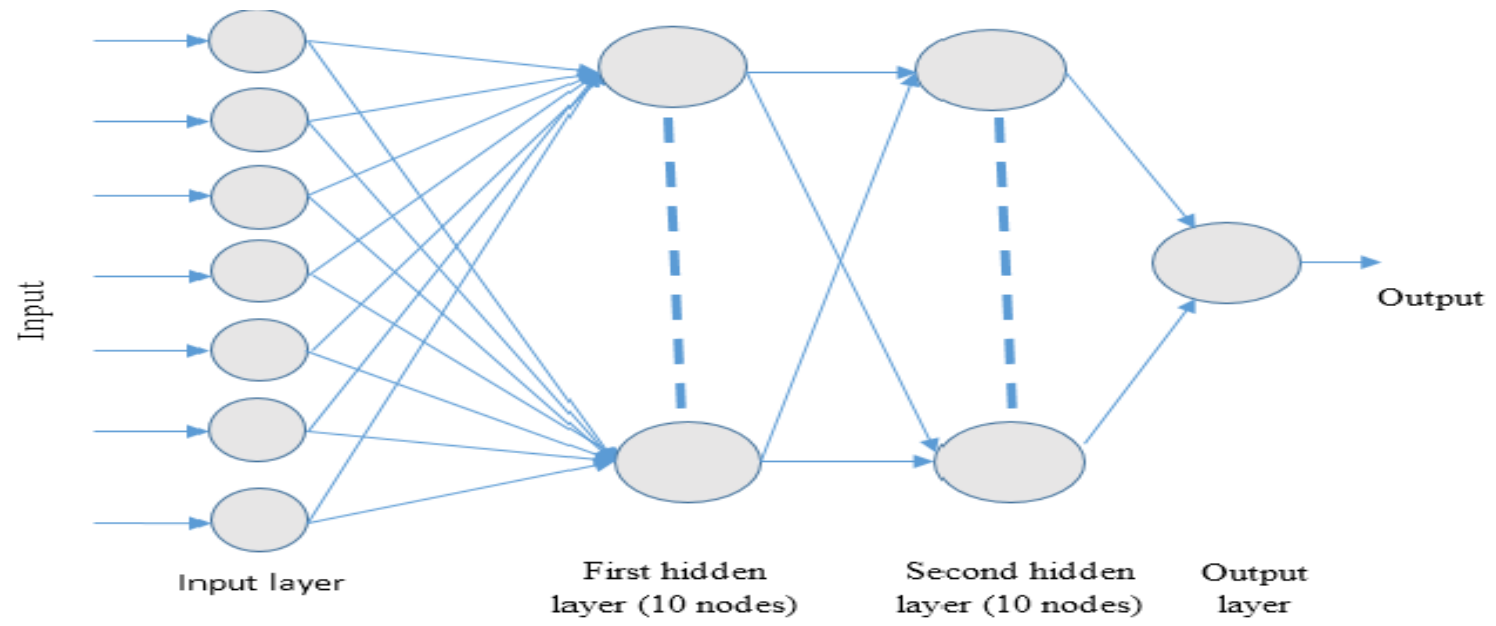

Figure 13 The optimum MLP architecture

Table 3 Comparative analysis for different training algorithm

\begin{tabular}{lcccc}
\hline \multirow{2}{*}{ Training Algorithm } & \multicolumn{2}{c}{ Training } & \multicolumn{2}{c}{ Validation } \\
\cline { 2 - 5 } & \% of Correlation & RMSE & \% of Correlation & RMSE \\
\hline Traingd & 53.7 & 0.16 & 53.7 & 0.16 \\
\hline Traingda & 64.2 & 0.15 & 64.7 & 0.15 \\
\hline Traingdx & 67.1 & 0.14 & 67.1 & 0.14 \\
\hline Trainlm & 74.3 & 0.13 & 74.4 & 0.13 \\
\hline
\end{tabular}

Table 4 Comparison for the different hidden layer sizes

\begin{tabular}{lccccc}
\hline No of hidden layer nodes & \multicolumn{2}{c}{ Training } & \multicolumn{2}{c}{ Validation } \\
\cline { 2 - 6 } & \% of Correlation & RMSE & \% of Correlation & RMSE & 0.13 \\
\hline Single layer with 10 nodes & 72.3 & 0.13 & 72.2 & 0.13 \\
\hline Single layer with 20 nodes & 72.2 & 0.13 & 74.4 & 0.13 \\
\hline Double layer with 10 nodes each & 74.3 & 0.13 & 73.7 & 0.13 \\
\hline Double layer with 20 nodes each & 73.6 & 0.13 & & \\
\hline
\end{tabular}

Table 5 Result of the optimum ANN model using the fixed training and validation data

\begin{tabular}{llll}
\hline Architecture & Training/ Validation & \% of Correlation & RMSE \\
\hline A BP-MLP with SIGMOID transfer function & Training & 74.3 & 0.13 \\
\cline { 2 - 5 } & Validation & 74.4 & 0.13 \\
\hline
\end{tabular}

\subsection{Training and performance of the TFCV-ANN} model

TFCV-ANN model was trained and validated. The TFCV method is more suitable and accurate method to measure the correctness of the model. Approximately $74 \%$ correct correlation was observed in this method. The detailed report is presented in Table 6 where percentage of correct correlation and RMSE are depicted. In Figure 14 and Figure 15, the results are illustrated for percentage of correct correlation found from the training data and validation data for each fold with corresponding error bar.

The optimum condition of the process parameters for the stated study of that particular tea factory was found out from the developed ANN model and the trend is presented in Table 7 by averaging the process parameters. 
Debashis Saikia et al.

Table 6 Results of the TFCV-ANN model

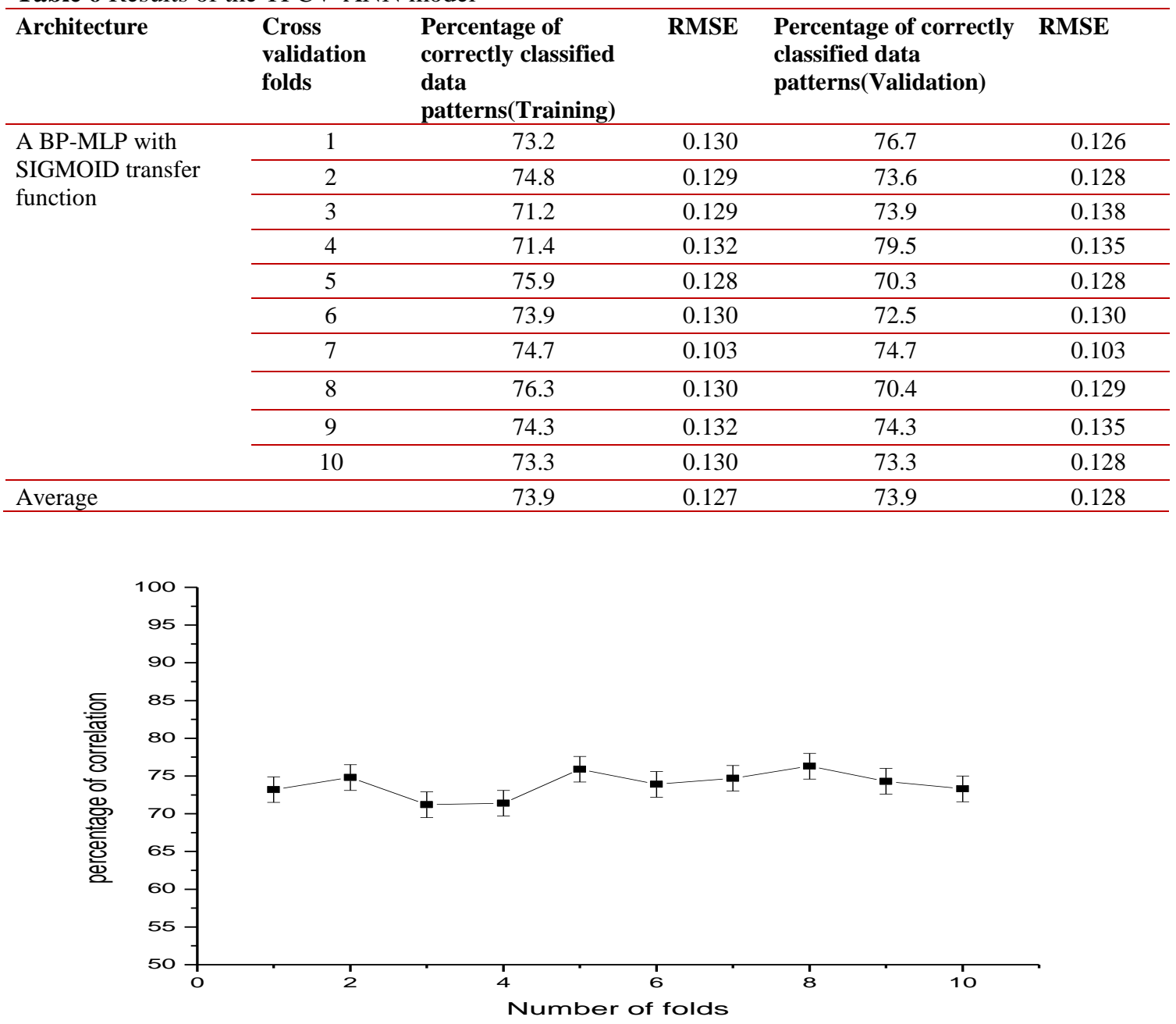

Figure 14 Percentage of correlation vs. number of folds with the error bar for training

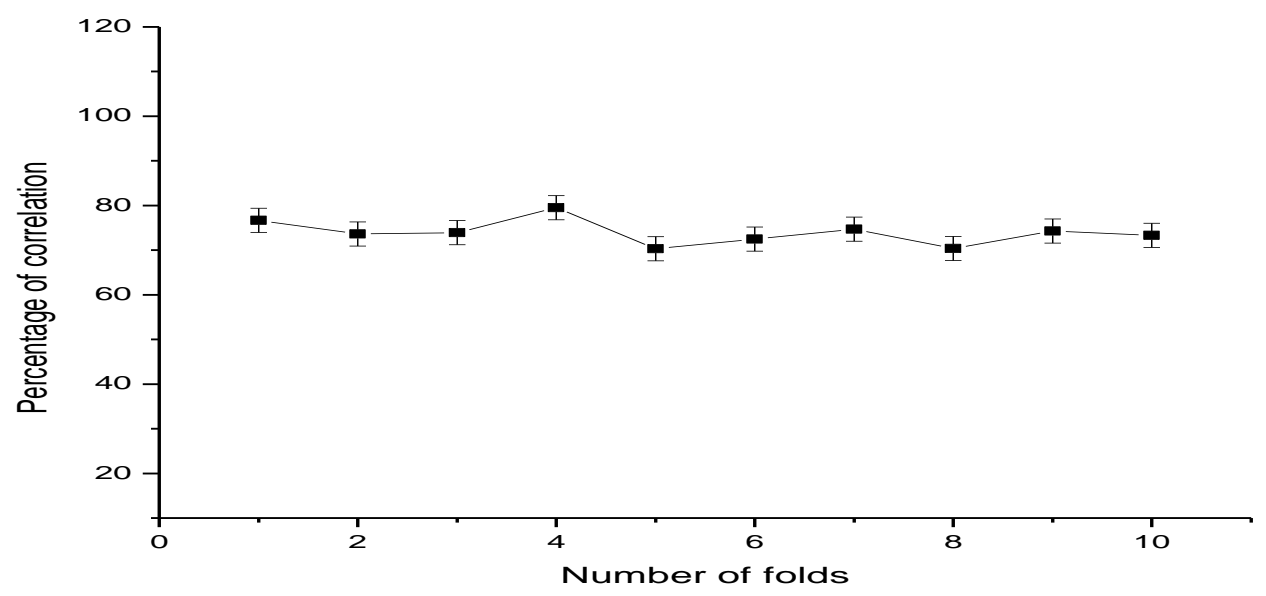

Figure 15 Percentage of correlation vs. number of folds with the error bar for validation 230 
Table 7 Typical trends of optimum conditions

\begin{tabular}{lll}
\hline Fermentation Room & & Dryer Inlet \\
\hline RH $(\boldsymbol{\%})$ & Temperature $\left({ }^{\mathbf{0}} \mathbf{C}\right)$ & Temperature $\left({ }^{\mathbf{0}} \mathbf{C}\right)$ \\
\hline 82 & 32 & 92 \\
\hline 92 & 28 & 90 \\
\hline 92 & 30 & 84 \\
\hline 93 & 30 & 78 \\
\hline
\end{tabular}

\section{Discussion}

The process conditions of tea manufacturing were collected by developed network based instrumentation from the factory. The corresponding tea quality was provided by human experts in the range of 0 to 10 . Principal component analysis was carried out by taking 100 representative samples of each group from 10 different groups of tea to visualize the pattern of the data. More than $93 \%$ useful information were stored in first two principal components and more than $99 \%$ useful information were stored in first three principal components. Maximum samples were clustered in well-defined manner, so it can be concluded that the correlation between the process parameters and OLR is confirmed.

The correlation between the process parameters and OLR was studied using an ANN based model and the optimum ANN model comprising of input layer with 7 nodes, two hidden layers having 10 nodes each and the output layer with one node was suggested. NCVANN model and TFCV-ANN model was implemented and found as below:

- Both models were compared and the results showed resemblance for percentage of correlation and RMSE in both the cases.

- Percentage of correlation and RMSE in this case was found more than $70 \%$ and 0.13 respectively which stands for good correlation between the process parameters and OLR.

- TFCV-ANN model was used to find the optimum condition of tea process parameters.

- The optimum values of the process parameters can be useful for controlling the processes to get the best quality tea
The novelty of this work over the previous work related to tea quality prediction is that this work has been carried out in the factory environment by installing the developed instrumentation system rather than in a controlled environment. Most of the previous works cited here are carried out with the end product and classified the tea quality accordingly. In this attempt it is focused on the possibility of quality improvement of tea by finding the optimum process conditions.

Limitation of the stated work is given below:

a. This work does not include the withering process parameters.

b. More numbers of sensor nodes as well as sensors can be incorporated for gathering more information which will lead to more accurate result.

\section{Conclusion and future work}

It is concluded that a relation between the process parameters and OLR is established by which prediction of tea quality can be done and tea quality can be improved by controlling the stated parameters with its optimum value.

In future, following works can be carried out-

1. Some more process parameters can be incorporated by associating more numbers of sensors and processes into account.

2. Some other robust classifiers like support vector machine (SVM) and radial basis function (RBF) based architectures can be used and comparison of all the models can be made.

3. Fuzzy-Neuro computing and different fusion based approach may also stand for good result. 


\section{Acknowledgment}

Department of Science and Technology, Govt. of India is acknowledged for providing INSPIRE Fellowship to one of the authors during the work. The authors of the paper acknowledge the authority and staff of tea factory for their help and support. The authors acknowledge the supports from Dr. Banty Tiru, Associate Professor, Dept. of Physics, Gauhati University. Mr. Manash Protim Goswami is also acknowledged for helping in installation of the instrument in the tea factory.

\section{Conflicts of interest}

The authors have no conflicts of interest to declare.

\section{References}

[1] Gonzalez JG, Coggon PT, Sanoerson G. A Research note biochemistry of tea fermentation: formation of $\mathrm{t}$ 2-hexenal from linolenic ACID. Journal of Food Science. 1972; 37(5):797-8.

[2] Bhattacharyya N, Seth S, Tudu B, Tamuly P, Jana A, Ghosh D, et al. Monitoring of black tea fermentation process using electronic nose. Journal of Food Engineering. 2007; 80(4):1146-56.

[3] Bhattacharyya N, Seth S, Tudu B, Tamuly P, Jana A, Ghosh D, et al. Detection of optimum fermentation time for black tea manufacturing using electronic nose. Sensors and Actuators B: Chemical. 2007; 122(2):627-34

[4] Temple SJ, Temple CM, Boxtel AJ, Clifford MN. The effect of drying on black tea quality. Journal of the Science of Food and Agriculture. 2001; 81(8):764-72.

[5] Sarnot SL. Need of electronic instrumentation in Tea industries. Technical report.

[6] Kumar PS, Basheer S, Ravi R, Thakur MS. Comparative assessment of tea quality by various analytical and sensory methods with emphasis on tea polyphenols. Journal of Food Science and Technology. 2011; 48(4):440-6.

[7] Samanta T, Cheeni V, Das S, Roy AB, Ghosh BC, Mitra A. Assessing biochemical changes during standardization of fermentation time and temperature for manufacturing quality black tea. Journal of Food Science and Technology. 2015; 52(4):2387-93.

[8] Sarma U, Boruah PK. Design and development of a relative humidity and room temperature measurement system with on line data logging feature for monitoring the fermentation room of tea factory. Sensors \& Transducers. 2011; 135(12):126-33.

[9] Sarma U, Boruah PK. Design and characterisation of a temperature compensated relative humidity measurement system with on line data logging feature. Mapan. 2014; 29(2):77-85.

[10] Saikia D, Boruah PK, Sarma U. Development and implementation of a sensor network to monitor fermentation process parameter in tea processing. International Journal on Smart Sensing and Intelligent Systems. 2014; 7(3):1254-170.

[11] Sarma U, Boruah PK. Design and development of a high precision thermocouple based smart industrial thermometer with on line linearization and data logging feature. Measurement. 2010; 43(10):1589-94.

[12] Xie C, Li X, Shao Y, He Y. Color measurement of tea leaves at different drying periods using hyperspectral imaging technique. Plos One. 2014; 9(12):e113422.

[13] Prasetya AT, Wibowo NA, Rondonuwu FS Determination of total quality of black tea fanning grade using near-infrared spectroscopy. JPhCS. 2018; 1097(1):012008.

[14] Saha P, Ghorai S, Tudu B, Bandyopadhyay R, Bhattacharyya $\mathrm{N}$. Tea quality prediction by sparse modeling of electronic tongue signals. IEEE Transactions on Instrumentation and Measurement. 2018; 68(9):3046-53.

[15] KC Y, Parajuli A, Khatri BB, Shiwakoti LD. Phytochemicals and quality of green and black teas from different clones of tea plant. Journal of Food Quality. 2020.

[16] Hidayat SN, Triyana K, Fauzan I, Julian T, Lelono D, Yusuf $\mathrm{Y}$, et al. The electronic nose coupled with chemometric tools for discriminating the quality of black tea samples in situ. Chemosensors. 2019; $7(3): 29$

[17] $\mathrm{Xu} \mathrm{M}$, Wang J, Zhu L. The qualitative and quantitative assessment of tea quality based on E-nose, E-tongue and E-eye combined with chemometrics. Food Chemistry. 2019; 289:482-9.

[18] Dutta L, Talukdar C, Hazarika A, Bhuyan M. A novel low-cost hand-held tea flavor estimation system. IEEE Transactions on Industrial Electronics. 2017; 65(6):4983-90.

[19] Zhu J, Chen F, Wang L, Niu Y, Xiao Z. Evaluation of the synergism among volatile compounds in Oolong tea infusion by odour threshold with sensory analysis and E-nose. Food chemistry. 2017; 221:1484-90.

[20] Zhi R, Zhao L, Zhang D. A framework for the multilevel fusion of electronic nose and electronic tongue for tea quality assessment. Sensors. 2017; 17(5):1007.

[21] Saikia D, Boruah PK, Sarma U. A sensor network to monitor process parameters of fermentation and drying in black tea production. Mapan. 2015; 30(3):211-9.

[22] Chen Q, Zhao J, Vittayapadung S. Identification of the green tea grade level using electronic tongue and pattern recognition. Food Research International. 2008; 41(5):500-4.

[23] Yu H, Wang J, Xiao H, Liu M. Quality grade identification of green tea using the eigenvalues of PCA based on the E-nose signals. Sensors and Actuators B: Chemical. 2009; 140(2):378-82.

[24] Yu H, Wang J, Yao C, Zhang H, Yu Y. Quality grade identification of green tea using E-nose by CA and ANN. LWT-Food Science and Technology. 2008; 41(7):1268-73.

[25] Dutta D, Sarma DK, Konwar M, Sharma S, Viswanathan G, Gairola RM, et al. Nowcasting of Yes/No rain situations at a station using soft computing technique to the radar imagery. 2010. 
[26] Sarma DK, Konwar M, Sharma S, Pal S, Das J, De UK, Viswanathan G. An artificial-neural-networkbased integrated regional model for rain retrieval over land and ocean. IEEE Transactions on Geoscience and Remote Sensing. 2008; 46(6):1689-96.

[27] Saikia D, Sarma DK, Boruah PK, Sarma U. An ANN model to estimate the impact of tea process parameters on tea quality. Journal of Circuits, Systems and Computers. 2015; 24(09):1550139.

[28] Chik Z, Aljanabi QA, Kasa A, Taha MR. Tenfold cross validation artificial neural network modeling of the settlement behavior of a stone column under a highway embankment. Arabian Journal of Geosciences. 2014; 7(11):4877-87.

[29] Palit M, Tudu B, Dutta PK, Dutta A, Jana A, Roy JK, et al. Classification of black tea taste and correlation with tea taster's mark using voltammetric electronic tongue. IEEE Transactions on Instrumentation and Measurement. 2009; 59(8):2230-9.

[30] Bhattacharyya N, Bandyopadhyay R, Bhuyan M, Tudu B, Ghosh D, Jana A. Electronic nose for black tea classification and correlation of measurements with "Tea Taster" marks. IEEE Transactions on Instrumentation and Measurement. 2008; 57(7):131321.

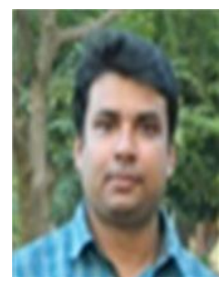

Debashis Saikia received his $\mathrm{Ph} . \mathrm{D}$ from Gauhati University under the faculty of technology. He is currently working as Assistant Professor in the Department of Instrumentation and USIC, Gauhati University. His research interests are Smart Sensor, Instrumentation for Tea Process and Sericulture, Soft Computing and Sensor Network. Email: dsaikia.10@gmail.com

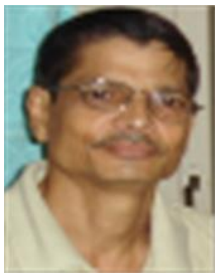

P. K. Boruah received the Ph.D degree from Gauhati University in 1980 . He was a Scientific Officer and head of Instruments Division under Forensic laboratory, Government of Assam for a period of 17 years. He also served as Research \& Development Manager, Assam Electronics Development Corporation for a period of 3 years. He retired as a Professor in the Department of Instrumentation \& USIC, Gauhati University. His research interest is Experimental Cosmic Ray Physics, Detectors \& Instrumentation, Signal Processing and Development of Smart Transducer Instrumentation \& Sensor Networks.

Email: PKB4@rediffmail.com

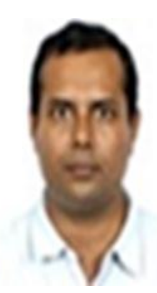

Utpal Sarma received the M.Sc. degree in physics and the Ph.D. degree from Gauhati University, Guwahati, India, in 1998 and 2010, respectively. In 1999, he joined the Department of Physics, B. Borooah College, Guwahati, as a Lecturer. He joined Gauhati University, as an Assistant Professor, in 2007, where he is currently a Professor. His current research interests include embedded system for Agro Industries, Sensor Instrumentation, and Micro Energy Harvesting Devices.

Email: Utpal.Sarma.IN@ieee.org 